\title{
An enterprise modelling approach for better optimisation modelling: application to the humanitarian relief chain coordination problem
}

\author{
Aurelie Charles • Matthieu Lauras
}

\begin{abstract}
Humanitarian supply chains (HSC) can be considered a new research area. The number of applied scientific publications has considerably increased over the past 15 years. About half of this research work uses quantitative techniques as optimisation decision-support systems. But due to the recentness of this academic area, researchers are finding it difficult to develop accurate, and above all, reliable mathematical models to support their steps towards improvement. This is particularly true concerning the crucial problems of coordination in HSCs. This paper tackles the issue by developing an original quantitative modelling support method. Based on enterprise modelling methodologies, we propose a business process modelling approach that helps in understanding, analysing, evaluating and then developing the formal expression of an HSC. Such a model, therefore, clearly has an added value for practitioners and should enable relevant quantitative models to be produced. Finally, an application on the emergency response processes of the International Federation of Red Cross is detailed in order to validate the relevance and the applicability of our proposal. This experiment allows all the variables and parameters that should be useful for improving the efficiency of the network to be identified.
\end{abstract}

Keywords Optimisation modelling · Humanitarian supply chains · Enterprise modelling $\cdot$ Coordination $\cdot$ Relief chains

\footnotetext{
A. Charles $(\varangle) \cdot$ M. Lauras

Universite Toulouse, Mines Albi, Albi, France

e-mail: aurelie.charles@mines-albi.fr

M. Lauras

Universite Toulouse, Toulouse Business School, Toulouse, France
} 


\section{Introduction}

The number of scientific articles dedicated to the study of the humanitarian supply chain (HSC), either general or focussed on a specific issue, was remarkably low 5 years ago. This has changed recently with the publication of a substantial number of papers related to disaster management. There were 120 publications registered in 2009 on this topic in the Science Direct database compared to only 20 publications in 1997.

According to Denizel et al. (2003), three types of research are classically used in OR/MS: management sciences, management consulting and management engineering. In management sciences, the goal is to develop new results to contribute to the body of knowledge in the discipline. As for management consulting, the goal is to solve practical problems using existing, standard methods. Management engineering is between the two, as its goal is to solve those practical problems for which it is necessary to adapt existing tools in fundamentally novel ways. Management engineering is by far the most widely used in the humanitarian context. This may be due to the relative youth of this area of research. If the articles are sorted by disaster contributions, more than half of the research published is on the development of analytical models followed by case studies and theory (one-fourth) (Altay and Green 2005). As for research methodologies, mathematical programming is the most frequently utilised method.

But few or no humanitarian organisations go as far as using optimisation-based decision-support systems. This goes against traditional recommendations found in the academic and business world. According to Simchi-Levi et al. (2003), a thorough logistics network analysis, for example, should consider complex transportation cost structures, warehouse sizes, manufacturing limitations, inventory turnover ratios, inventory costs and service levels. These issues typical in humanitarian world could benefit from the use of optimisation-based decision-support systems that can solve large-scale problems efficiently.

OR/MS researchers are no doubt aware that the main criteria of the success of optimisation-based approaches consists in producing a complete and representative mathematical model of the studied system. But considered an art by many and weird science by some, mathematical modelling is not as simple as it seems. This is particularly true in the humanitarian context, as in all new research areas, where researchers have difficulty identifying the right decision variables and parameters to be able to develop accurate and relevant analytical models. This paper tackles the issue by focussing on modelling techniques rather than solution algorithms.

Based on enterprise modelling (EM) methodologies, the present article proposes a conceptual modelling approach that aids in understanding, analysing, evaluating and then developing the formal expression of an HSC. Such a model, therefore, clearly has an added value for practitioners and should allow reliable quantitative models to be produced. From an academic point of view, we are not implementing a typical OR/MS method for developing analytical models, but instead, we are proposing a complementary approach, or to be more specific, one that should precede it. EM enables researchers to keep a business view of operations. With their needed cuts, OR/MS analytical models may move away from such a view. We agree with Barr on the fact that the disciplines of computer science and operations research have been linked since 
their origins, with decision support modelling being one of the connections between these two areas (Barr et al. 1997). Thus, we are referring to logical models as found in computer science (Gruninger and Fox 1995) to facilitate mathematical modelling expression.

Our findings will be presented in three parts.

First, we will provide the reader with a brief overview of what a relief operation is and how it evolves over time. Knowing that disaster relief is approximately $80 \%$ logistics (Van Wassenhove 2006), we will also present a global model of an HSC, briefly underlying the differences with common commercial supply chains. We will provide a brief analysis of the literature on the key elements that constitute a successful humanitarian operation. This literature highlights the need for improvement in terms of coordination capabilities, which drives our future application case.

Second, a specific business process modelling approach to formalise humanitarian operations will be described. This approach originates from the usual process improvement strategy proposed in enterprise modelling (EM) standard ISO19439 (AFNOR 2006), but some complementary developments have been included to take into account humanitarian specificities. Based on these logical models, a step to support identification of relevant decision variables and parameters is useful for the development of relevant and reliable quantitative models in a humanitarian context.

Finally, we will portray an application case elating to the sudden-onset International Federation of Red Cross (IFRC) business processes.

\section{Basics of relief chains}

\subsection{Salient features of humanitarian supply chains}

Various approaches and definitions (Kilger and Stadtler 2002; Mentzer et al. 2001; Arnold and Chapman 2004) consider supply chain management (SCM) as coordinated systems that manage flows. Cooper and Ellram (1993), for example, define SCM as an integrative philosophy for managing the total flow of a distribution channel from the supplier to the ultimate user. Simchi-Levi et al. (2003) specify that SCM is a set of approaches utilised to efficiently integrate suppliers, warehouses and stores, so that merchandise is produced and distributed at the right quantities, to the right locations, and at the right time, in order to minimise system-wide costs while satisfying service level requirements. If we exclude some unsuitable terms such as "user", "store" or "service level", the concept of SCM explains what humanitarian organisations, suppliers and donors must do to minimise the impact of a crisis: this is the humanitarian supply chain (HSC).

According to Van Wassenhove (2006), HSCs are about 15 years behind their privatesector counterparts who realised long ago the importance of using efficient supply chains. He also explains that humanitarian logisticians have been struggling for recognition and that humanitarian organisations are just beginning to wake up to the fact that logistics are crucial. Indeed, the effectiveness of the supply chain is a critical factor in the performance of humanitarian relief organisations, yet this sector has been slow to make much-needed investments in logistics (W.E.F. The Synergos Institute 2005). 
Although the humanitarian world has become aware of logistics, work in the context of natural or man-made disasters is very different from logistics in the business context. Several authors (Van Wassenhove 2006; Beamon 2004; Stephenson 2005; Oloruntoba and Gray 2009; Kovcs and Spens 2007) have tried to identify the characteristics of the former's particular context. We have retained six different categories:

- the Stakeholders,

- the Categories of Flows Managed,

- the Funding Process,

- the Dynamics and the Complexity of the Environment,

- the Humanitarian Operation Life Cycle, and

- the Humanitarian Space.

The Stakeholders The humanitarian distribution channel goes through many different stakeholders, that we call Strategic Humanitarian Units (SHU) starting from suppliers and going to beneficiaries (but not to consumers or users). These SHUs are of a different nature: they are international agencies such as the World Food Programme (WFP), international non-governmental organisations (INGOs) such as Care International, non-governmental organisations (NGOs), implementing partners, the military, donors, private companies and governmental agencies. All these SHUs have, to some extent, the following proprieties:

- They are under resourced, with limited skills availability and high employee turnover that limits institutional memory and efficiency.

- Ineffective leverage of technology (i.e. non- robust equipment) and in particular, information systems that are relatively basic. Many relief logistics departments rely on manual systems without any Information Technology.

- Command / control systems are lacking.

- Several operations need to be done at the same time.

In addition, not all of these stakeholders have the same incentives.

The Categories of Flows Managed The humanitarian distribution channels manage the traditional categories of flows, but these present some specificities:

- Physical flows are material (food, relief items, etc.) and human (organisational skills).

- Informational flows (order transmission, tracking and coordination of physical flows) that are poorly structured and managed.

- Financial flows that are unilateral (from donors).

Moreover, because the media places such high pressure on agencies to compete for visibility, organisations have to consider the media flow, to better control what is within their sphere of influence. For instance, Van Wassenhove (2006) explains that ineffective use of the media by humanitarian organisations can lead to inundations of unsolicited donations to the supply chain, with resulting bottlenecks, instead of the much-needed resources.

The Funding Process HSC are financed by donors, like governments, private companies, or individuals, through a funding process. The funding process is a channel for 
donations from individual people or donor organisations to the beneficiaries (through several SHUs). Thus, contrary to Commercial Supply Chains, the financial flows are not parallel with the material flows.

The Dynamics and the Complexity of the Environment The dynamics of HSCs are very specific because they endeavor to respond to certain vital needs due to sudden or long-term crises. An HSC does not start with a customers expression of needs and does not want to make a profit. Under these conditions, it is quite difficult to apply best practices in terms of planning and scheduling. There is evidence of a frequent lack of planning in relief supply chains, resulting in inefficiencies. For example, the overuse of expensive and unsafe air charters, failure to pre-plan stocks, congestion at ports caused by unplanned deliveries, delivery of useless or unwanted items to disaster victims and a lack of inter-organisational collaboration for information systems (Oloruntoba and Gray 2009). Generally, an SHU has to

- assess needs;

- consider unforeseeable conditions and very short time frames;

- work under emergency conditions and to be agile; and

- manage despite a lack of transparency. The environment of HSCs includes several specific characteristics that intensify its complexity:

- A politically volatile climate in which humanitarian organisations have to operate;

- Apolitical missions;

- A high level of uncertainty in terms of demand, supply and environment.

Other constraints on managing an HSC come from unforeseeable, complex, particular and unstable external actors such as local governments (where the crisis takes place), donor governments, the military (third-party service providers), or privatesector logistics providers (i.e. transportation, warehousing).

The Humanitarian Operation Lifecycle If we consider a project to be a temporary endeavour undertaken to achieve a particular aim, then HSC operations can be defined as a project. In fact, humanitarian organisations are responsible for producing relevant outputs and hence they must be constantly aware of the project goal (minimising the impact of a crisis), project purpose, and of course, the internal measurements of project management efficiency. Concretely, there are two kinds of project environments for implementing humanitarian logistics operations:

- Slow-onset disasters: Droughts, epidemics, famine/food insecurity, population movements, and man-made disasters.

In this case, the focus is on capacity building, using national staff, cost savings, low budgets, planning and scheduling and long time frames.

- Sudden-onset disasters: Hurricanes, cyclones and typhoons, earthquakes, floods, volcanic eruptions, technological and man-made disasters.

In this case, the focus is on providing medical assistance, providing food and nonfood items, launching appeals, globally assessing needs, using international staff, high budgets and very short time frames.

Figure 1 distinguishes the four different phases in the life cycle of a humanitarian operation directly inspired from Van Wassenhove (2006) and Pettit and Beresford 


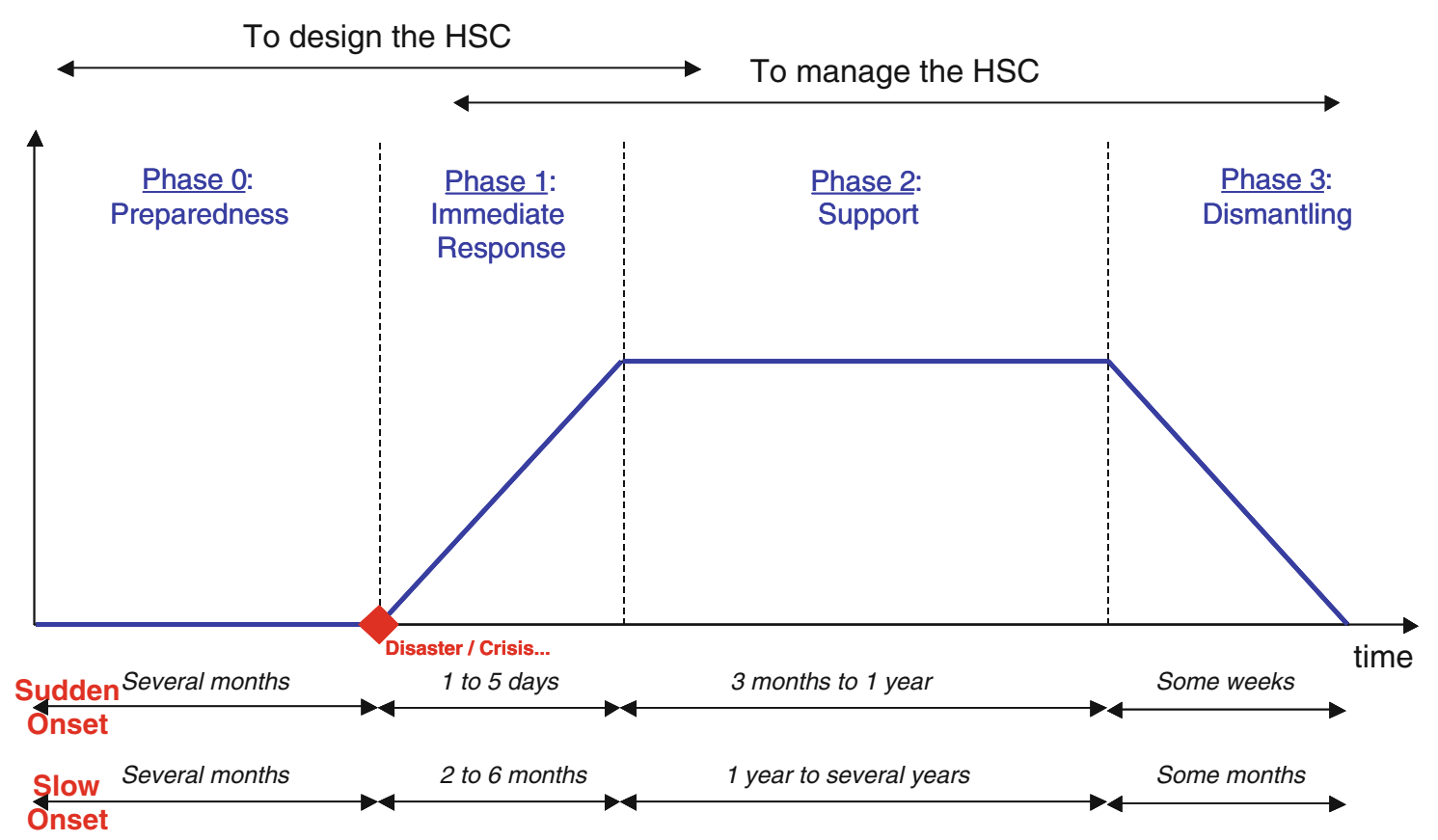

Fig. 1 The humanitarian operation life cycle (inspired from Van Wassenhove 2006; Pettit and Beresford 2005)

(2005): Preparedness, Immediate Response (Ramp Up), Support (Maturity) and Dismantling (Ramp Down). The duration of the operations varies according to the function of the project's characteristics (sudden- or slow-onset). Nevertheless, the duration is much less important than it would be for any comparable industrial project. This linear life-cycle may also be represented as a learning loop, where dismantling is followed by preparedness (Safran 2003).

The Humanitarian Space Humanitarian organisations live by their principles of humanity, neutrality and impartiality. In other words, they will help everyone in need wherever found; they will not influence the outcome of a conflict with their intervention; and they will not favour one group of beneficiaries over another. These principles define the 'space', both physically and virtually, in which they need to be able to operate to do their job effectively (Tomasini and Wassenhove 2009). A set universal minimum standards in core areas has been defined by The Sphere Project (2004).

Figure 2 summarises how an HSC operates.

\subsection{Key elements for a successful humanitarian operation}

"A successful humanitarian operation mitigates the urgent needs of a population with a sustainable reduction of their vulnerability in the shortest amount of time and with the least amount of resources" (Tomasini and Van Wassenhove 2005). Consequently, a successful response to a disaster is not improvised and must be prepared to be effective. Humanitarians have begun to heed the lessons learnt from previous disasters and realise that they have to work hard not only during disasters but also between them (Tomasini and Wassenhove 2009). According to Van Wassenhove (2006), preparedness consists 


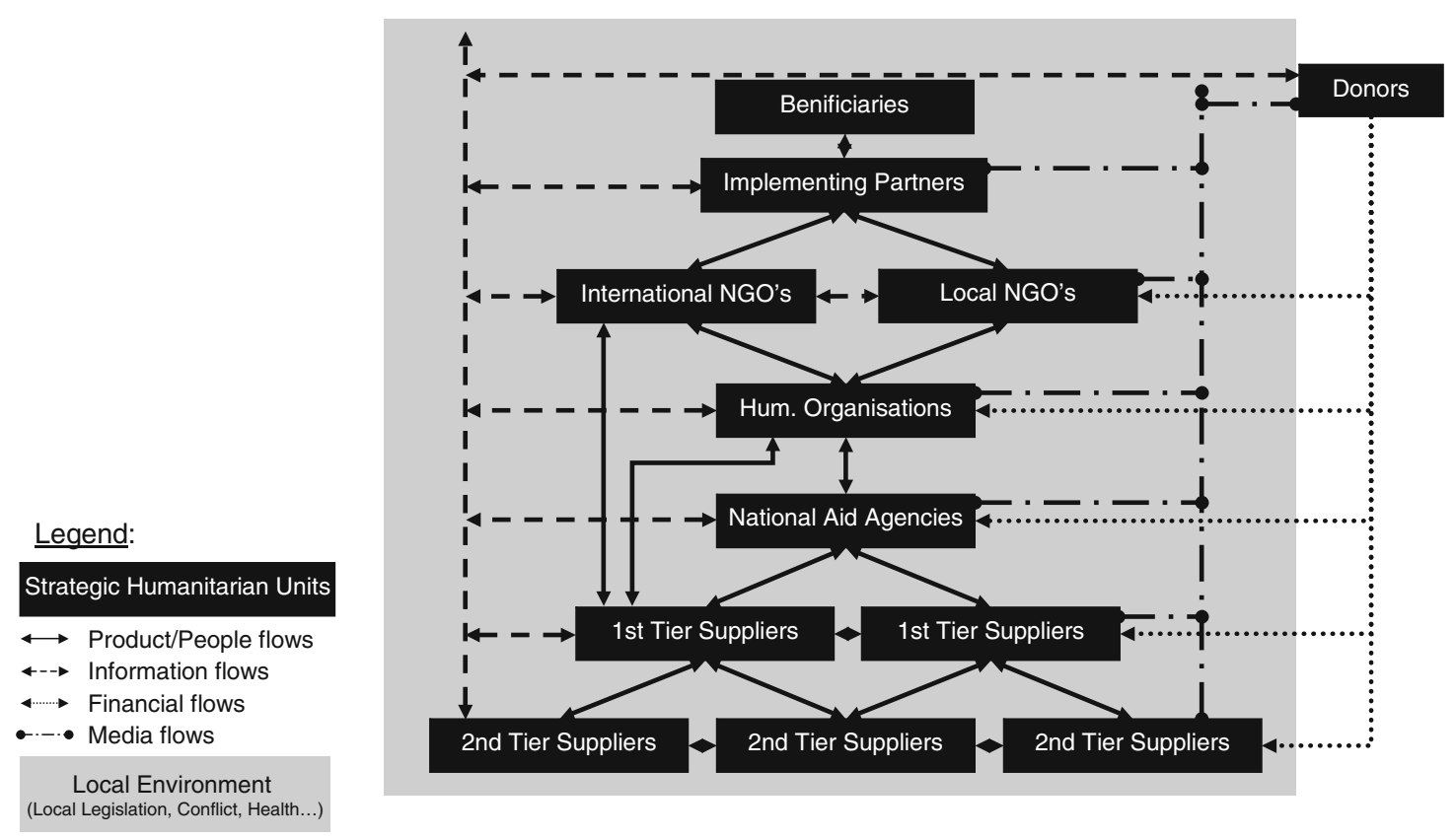

Fig. 2 Global model of a humanitarian supply chain (inspired from Oloruntoba and Gray 2009; Handfield and Nichols 2002)

of five key elements that have to be in place to produce effective results. These in turn lead to effective disaster management. They are as follows:

1. Knowledge management: Learning from previous disasters by capturing, codifying and transferring knowledge about logistics operations. See Tomasini and Van Wassenhove (2005), Bui and Sankaran (2001), Kaiser et al. (2003) and Benini et al. (2003).

2. Financial resources: Preparing sufficient funds to prepare and initiate operations and ensure that they run as smoothly as possible. See Jahre and Heigh (2008) and Stapleton et al. (2009a) for details.

3. Human resources: Selecting and training people who are capable of planning, coordinating, acting and intervening where necessary. The problem of human resources in humanitarian operations is probably the most neglected one in terms of academic research. Nevertheless, many authors (Van Wassenhove 2006; W.E.F. The Synergos Institute 2005; Beamon 2004; Stephenson 2005; Oloruntoba and Gray 2009) have demonstrated how crucial this problem is. The shortage of qualified staff and the excessive turnover often have harmful consequences on the management of crises. However, methods exist in business management that should be adapted to design relevant skills management systems for the humanitarian sector.

4. The community: Finding effective ways of collaborating with other key players such as governments, the military, business and other humanitarian organisations. See Stephenson (2005), Benini (1999) for an application of "organisational design" best practices to humanitarian relief efforts. Pettit and Beresford (2005) have detailed the relations between military and humanitarian organisations. See also Refugee Studies Centre (2007) and Van Wassenhove and Samii (2003) for details of centralised coordination regarding a UN agency. 
5. Operations and process management: Recognising logistics as a central role in preparedness. Then setting up goods, agreements and means needed to move the resources quickly. Several papers discuss operations and process management in HSCs. They study mainly the improvement of unitary operations or business processes in a humanitarian context. Examples include transportation and inventory management (Stapleton et al. 2009b; Clay Whybark 2007; Akkihal and Blanco 2006 among others); the development of flexible technology and software for supporting humanitarian operations (Blecken and Hellingrath 2008); metrics and performance measurement in a humanitarian context (Davidson 2006; Beamon and Balcik 2008 among others).

Most of the research that we have referred to earlier is quantitative and has been implemented with optimisation methods. On the contrary, the "community" key element seems to have been studied only in a qualitative manner mainly through case studies (Tomasini and Wassenhove 2003, 2009; Van Wassenhove and Samii 2003; Chandes and Pache 2010). The trouble is that the coordination processes are very complex to understand, and consequently very difficult to translate into a mathematical formula. In fact, stakeholders operate at different levels of an HSC and have to guarantee the coherence of their actions, especially when several members of the network operate at the same time in the same place. In addition, practitioners and researchers have a great amount of difficulty designing quantitative models that allow them to coordinate all operations in a consistent way and in general, to improve the performance of an HSC. The purpose of this paper was to explore this problem of developing quantitative models in a relief chain context with a particular focus on coordination aspects that will

1. counteract the fact that "effective coordination of humanitarian assistance activities remains elusive" (Stephenson 2005).

2. Facilitate the implementation of optimisation techniques on HSCs in order to optimise their performances.

The following paragraphs aim to clarify the various facets of coordination in humanitarian operations.

\subsection{Coordination: a current problem}

Lack of coordination has often been listed as a major weakness of humanitarian operations (Stephenson 2005; Kovcs and Spens 2007; Refugee Studies Centre 2007; Balcik et al. 2010; Van Wassenhove and Samii 2003). Classically, the problem of humanitarian operations is that at any one time, there can be as many as several hundred humanitarian organisations at the scene of a disaster, not always acting in a coordinated fashion (Van Wassenhove 2006). Consequently, there can be too many participants in the field without a clear division of work (Van Wassenhove 2006). In addition, the communication between stakeholders can be far from optimal. It is easy to understand that two stakeholders having different incentives will have difficulties sharing information. On the other hand, two stakeholders having the same principal activities should be able to align their operations in order to ensure a proper distribution of aid. And yet, a survey 
of logisticians that participated in the tsunami relief operations showed that just over half the logisticians $(56 \%)$ reported working with other agencies in setting up their supply chains (Thomas and Kopczak 2005). All these factors contribute to complexity in the delivery of relief.

To summarise, the bigger the disaster, the greater the number of humanitarian organisations that will have sufficient funding to participate in the humanitarian response and the more difficult coordination will be. Many coordination modes exist as selforganising systems or centralised systems (Charles 2010). The diversity of stakeholders and the variability of their presence and strength from one disaster to another sometimes makes it very difficult to find and implement the appropriate coordination mode. In the following section, we propose a framework that identifies the main determinants of humanitarian coordination.

\subsection{Key determinants of humanitarian coordination}

Malone and Crowsten have illustrated the difficulty of defining coordination and also the variety of possible starting points for studying the concept (Malone and Crowsten 1994). This section summarizes the key determinants of coordination in the context of humanitarian aid.

Mobilisation and allocation Humanitarian organisations have to globally manage and control many different solicitations and operations at the same time. Because they are under resourced, they have to define priorities in order to properly dispatch the funds and, of course, the personnel. This is not always easy. According to Thomas and Kopzac, "in order to effectively respond to the Tsunami, 88\% of large aid agencies surveyed had to pull their most qualified staff from the ongoing humanitarian operations in Darfur" (Thomas and Kopczak 2005). Globally, this is a problem of balancing available means.

Coherence and efficiency The majority of humanitarian organisations fulfil various SHUs in the HSC. A typical example is the International Federation of Red Cross (IFRC) that have headquarters in Geneva, three Relief Logistics Units (in Panama, Dubai and Kuala Lumpur) and more than 180 National Societies around the world. Consequently, when a crisis occurs, headquarters has to guarantee the coherence and above all the efficiency of the global action of the network on this crisis. SHUs must synchronise their actions in order to be increasingly effective and responsive. Globally, this is a problem of synchronisation.

Empowerment and best practices The two precedent components of coordination needs relate to phases 1, 2 and 3 of the life cycle (Fig. 1). But phase 0 could also be included in the coordination. Indeed, during the preparedness phase, a humanitarian organisation should capitalise on its past experiences in order to define best practices in terms of supplier selection, business processes, skill management, etc. This is one of the gap addressed by the humanitarian reform, which is about "making the international humanitarian community more structured, accountable and professional" 
(IASC 2007). A survey on the value added of the reform indicates that "while many have not yet seen added value, relatively few believe that clusters are useless or going in the wrong direction" (IASC 2007). However, according to many humanitarian workers, "the success or failure of humanitarian response and coordination is too often dependent or personalities". The independent 2007 Cluster Approach Evaluation Report noted that "... attributing everything to personality underplays the degree to which institutions can and do shape the behaviour, practices, and skills of individuals. Yet the humanitarian community has many serious weaknesses in managing human resources: from recruitment to training to appraisal" (The International Council of Voluntary Agencies 2008). The aim of this coordination should be to ensure the use of these best practices during future operations. Moreover, the personnel clearly have to learn from each other in order to be more efficient in the future. Of course, the objective is not standardisation because each crisis is unique. Globally, this is a problem of training.

To summarise, coordination seems to include three key determinants:

1. Balancing: To mobilise and properly allocate funds and skills for different crises at a given time.

2. Synchronisation: To guarantee the coherence and efficiency of a relief operation.

3. Training: To facilitate the empowerment amongst the network members and the implementation of best practices.

To achieve en effective coordination, this framework suggests that relevant operation reports, formalised strategies, responsive business processes, formal procedures, interoperable Information Systems and a responsive and efficient logistical network should be required.

\section{An enterprise modelling approach to support optimisation modelling}

\subsection{Principles}

Our proposition consists in establishing a conceptual model of an existing HSC in order to be able to extract a quantitative model to optimise parts of an HSC through OR techniques. The proposed methodology can be broken down into two phases:

1. The first phase corresponds to the implementation of an EM modelling approach in the particular context of humanitarian relief operations. To reach this goal, we propose to develop a dedicated humanitarian EM framework and its related Business Process Modelling techniques.

2. The second phase is the mining of previous conceptual models to extract the main components of future quantitative models that could be used to improve the performance of an HSC. The quantitative models considered address different key elements for a successful humanitarian operation described in the previous section. In this paper we will illustrate our proposition by studying several aspects of coordination problems in the case of a sudden-onset disaster. 


\subsection{Step 1: Enterprise modelling approach}

EM could be defined as the art of externalising knowledge which adds value to an organisation or needs to be shared (i.e. to describe elements of the organisation). In other worlds, the use of EM enable to build comprehensive figures, which can explain it far better than any kind of long complicated explanation could. It also enables to graphically formalise a given knowledge, and therefore optimises its usage. The major advantage of EM is that it fosters building a common consensus on how operations work or should work. The EM approach brings a number of methods and tools for representing the structure, behaviour, components and operations of a business entity in order to understand, (re)engineer, evaluate and even control business operations and performance. Other characteristics include the fact that we can implement this approach within a single organisation as well as within a distributed organisation. According to Vernadat (1996), there are five major motivations for EM: management of system complexity, better management of all types of processes, capitalisation of enterprise knowledge and know-how, Business Process Reengineering and enterprise integration. These motivations have already been described by several humanitarian workers. They all agree that "there is a need to build capacity in preparedness to work hard during disasters but to work even harder between disasters" (Van Wassenhove and Samii 2003). Thus, as humanitarian workers have formulated, "by starting with the overall picture of needs, we might be able to better agree on where the priorities lie and how we can better respond to gaps" (The International Council of Voluntary Agencies 2008).

A typical framework for enterprise modelling Since 2001, a shared framework for EM has been available. In this norm (AFNOR 2001), and in its successor (AFNOR 2006), three axes are given to drive the analysis:

- The Genericity, which defines the level of detail associated with the model.

- The Model Life Cycle, which is "the set of distinguishable phases and steps an entity may go through from its creation until it ceases to exist".

- The View, "a structured representation which is a selective perception of an enterprise model." Model views are used to emphasise the aspects that are relevant to the modeller and the model user's particular interests and context, i.e. function, information/decision, resource or organisation (Fig. 3).

Adaptation of the framework to fit humanitarians specificities As seen earlier, HSCs are project oriented. The response varies according to the typology of crises, the nature and number of the stakeholders, the complexity of the environment, and so on. A brief overview of the various HSCs that can be implemented is necessary prior to implementing the Enterprise EM approach in order to define the scope of the study. As discussed earlier, there are two kinds of project environments for implementing humanitarian logistics operations: slow-onset disasters and sudden-onset disasters. For each of these types of disasters, the supply chain and the amount of resources needed will also differ depending on the phase of the operation (see Fig. 1). Moreover, the humanitarian distribution channels go through many stakeholders. These stakeholders 


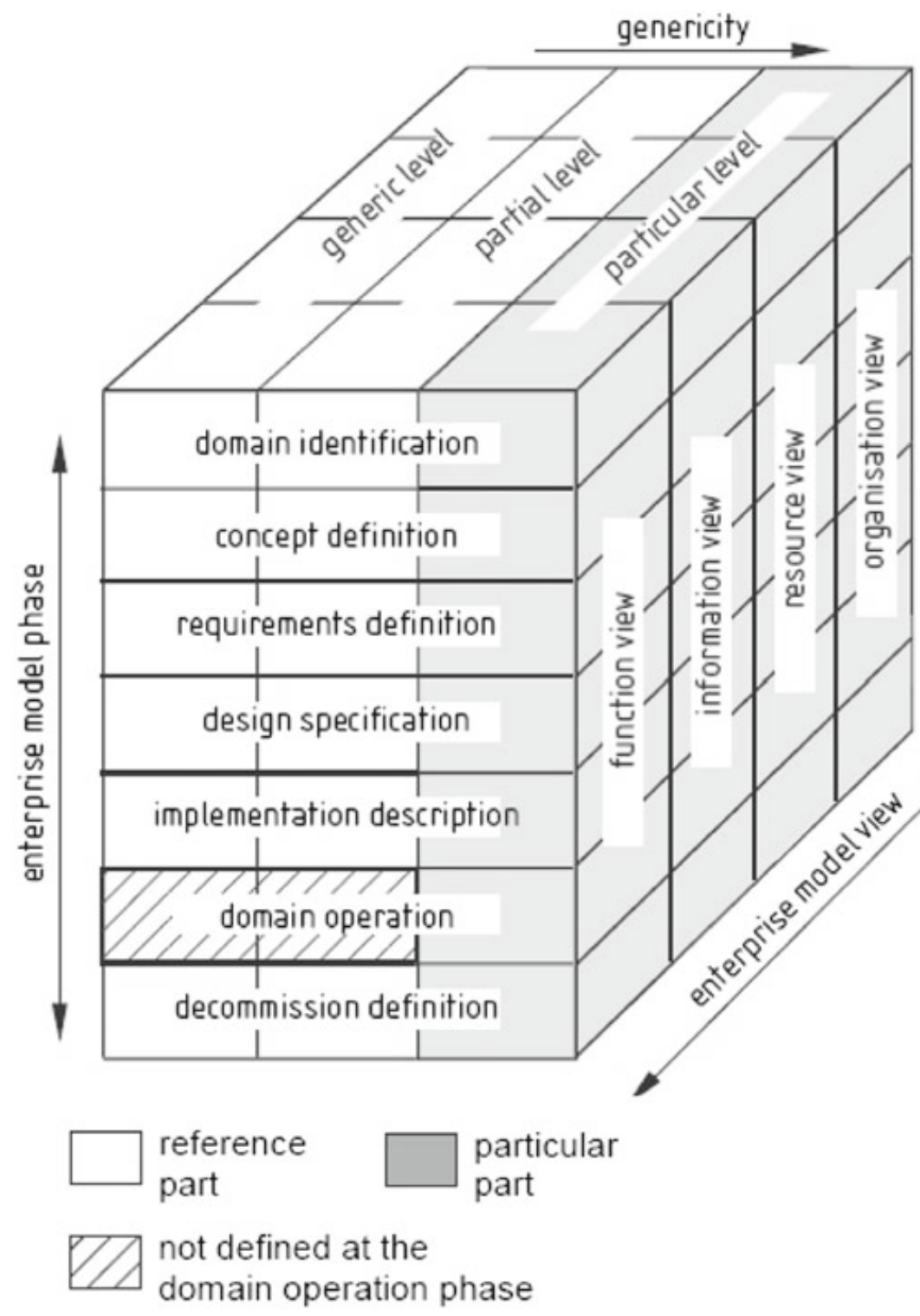

Fig. 3 Overview of the framework for enterprise modelling (AFNOR 2006)

are of different natures; they have different incentives and means of action. Depending on their presence or not in the field, the response varies drastically.

To summarise, we can say that the framework proposed in the norm ISO 19439 (AFNOR 2006) can be applied, but with minor modifications. The first concerns the life cycle stages. Instead of the seven stages recommended by the norm, humanitarians will focus on the four phases of their supply chain management, i.e. preparedness, immediate response, support and dismantling. This is a limitation of the study. Yet it enables humanitarians to focus on the most important phases of the operations, to limit the number of models and to reduce the time and resources needed to undertake such demanding work. The second modification lies in the genericity. According to the norm, the study should start with generic concepts, then specialise to a specific enterprise. In our case, no shared generic way of managing the supply chain exists. Moreover, the idea is to focus either on specific best practices and generalise them, or on specific gaps and bridge them. Consequently, instead of going from the generic 
Table 1 Adaptation of the methodological framework to take into account humanitarian specificities

\begin{tabular}{|c|c|c|}
\hline & ISO 19439 & $\begin{array}{l}\text { Adaptation to the modelling of } \\
\text { humanitarian operations }\end{array}$ \\
\hline Modelling levels & $\begin{array}{l}\text { "For different life cycle stages (from } \\
\text { requirements definition to design } \\
\text { specification to implementation } \\
\text { description)" }\end{array}$ & $\begin{array}{l}\text { For different life cycle stages (from } \\
\text { immediate response to dismantling) }\end{array}$ \\
\hline Genericity & $\begin{array}{l}\text { Specialisation, i.e. "providing generic } \\
\text { concepts which are then specialised } \\
\text { to a particular industry sector and } \\
\text { finally to a specific enterprise" } \\
\text { (from generic to partial, then } \\
\text { particular level) }\end{array}$ & $\begin{array}{l}\text { Generalisation, i.e. "the progression } \\
\text { from one or more particular concepts } \\
\text { to a more general concept which } \\
\text { represents [the modeller and } \\
\text { the model user] shared characteristics } \\
\text { or essential qualities" }\end{array}$ \\
\hline Views & $\begin{array}{l}\text { "Classifying concepts by four areas of } \\
\text { concern or modeller viewpoints } \\
\text { (function, information, resource and } \\
\text { organisation)" }\end{array}$ & \\
\hline
\end{tabular}

level to the specific, we recommend going the other way around, namely from the specific level to the generic. As for the view axis, the classification given by the norm is valid for humanitarians. The only difference we would recommend concerns the exhaustiveness of the study. According to the norm, all points of view for all phases of the operation life cycle should be studied. Yet again, as this is a time- and resourceconsuming process, and knowing how crucial these two elements are for humanitarian organisations, we suggest restricting the studies to the most pertinent models, depending on the needs identified (Table 1).

The response process can differ depending on the situation (the nature of the crisis, ability of the affected country to face the disaster, volatility of the environment, etc.). And from one organisation to another, it can also vary tremendously. Because of these variations, a clear specification of the scope, coverage and level of detail (crisis typology, targeted stakeholders, etc.) of the EM approach has to come with the model. Indeed, for example, working on a global model is only relevant for a high level of analysis and has a limited interest for a deeper analysis.

Business Process Modelling Notation (BPMN) to model the functional view Many methods and tools have been developed for modelling organisations. The choice of the most appropriate depends mostly on the modeller's viewpoint(s) and the aim of the study.

Even though different Business Process Modelling techniques could be envisaged, it is not the purpose of the present study to discuss such a choice. We have chosen to work with the Business Process Modelling Notation (BPMN) standard (Object Management Group 2004). This standard pays particular attention to both the sequencing of operations and the flows. It also gives the opportunity to study the interfaces, which facilitates the discussion of coordination and synchronisation problems. The four basic categories of BPMN elements are flow objects, connectors, artifacts and swimlanes (Object Management Group 2004).

According to White and Miers (2008), an event is something that "happens" during the course of a business process. An activity is a generic term for work that the 
company performs. A gateway is used to control the divergence and convergence of the sequence flow. Thus, it will determine traditional decisions, as well as the forking, merging and joining of paths. A sequence flow is used to show the order (the sequence) that activities will be performed in a process. A message flow is used to show the flow of messages between two separate process participants (business entities or business roles) that send and receive them. In BPMN, two separate pools in the diagram represent the two participants. An association is used to associate data, text and other artifacts with flow objects. Associations are used to show the inputs and outputs of activities. A pool represents a participant in a process. A lane is a sub-category within a pool and is used to organise and categorise activities.

\subsection{Step 2: Optimisation modelling approach}

Optimisation-based decision-support systems are concerned with developing and applying models and concepts that may prove useful in helping to illuminate management issues as well as designing and developing new and better systems (The Institute for Operations Research and the Management Sciences 2011). This kind of decision support system is based on a mathematical model. Mathematical modelling problems are often classified as black-box or white-box models, according to how much a priori information is available on the system (Bender 2000). A black-box model is a system for which there is no a priori information available. A white-box model is a system where all the necessary information is available.

Virtually all the quantitative models are located somewhere between these two kinds of models. Usually, it is preferable to use as much a priori information as possible to make the mathematical model more accurate. Indeed, the white-box models are usually considered to be easier to work with and generally to have better behaviour. Often the a priori information comes in the form of knowing the type of functions relating different variables and parameters (Hangos and Cameron 2001).

In the black-box model, both the functional form of the relations between variables and the numerical parameters in these functions are estimated. Using a priori information could result in, for example, a set of functions that probably describe the system adequately. But most of the time, there is no a priori information available. In that case the challenge consists in using the most general variables and parameters possible to cover all the different options. Consequently, there is a serious risk to the relevance of the mathematical model and to its behaviour (Hangos and Cameron 2001; Gershenfeld 1999)

Obviously, optimising an HSC assumes a black-box model due to the youth and the low quantity of the existing explicit knowledge. Our proposition consists in using previous conceptual models (see Step 1) in order to target important elements in the humanitarian system under consideration. These elements should be the variables and the parameters of the mathematical model.

In practical terms, the BPMN notation selected in the previous step to represent the functional view is a perfect means for showing the material and informational flows in the supply chains. The methodology that we propose to implement is the following:

1. Selecting an activity that contributes directly to the added value of the business process (i.e. that contributes directly to the relief of the beneficiaries). 
2. Identifying input/output flows of each activity in order to extract the input/output variables.

3. Extracting from each activity the different parameters (costs, cycle time, etc.). The next part proposes an implementation of our proposition on the IFRC case.

The selection of activities with a direct contribution to operations facilitates the distinction between decision variables, which are linked with value-added activities, and input data, linked with other activities.

\section{Application to the IFRC emergency response}

There are two options for studying the answer to a given humanitarian crisis: either we study the overall response linking all stakeholders' activities, or we focus on one stakeholder and map only its activities. The present article will present one application of our approach: the supply chain implemented by one stakeholder, the International Federation of the Red Cross and Red Crescent Societies (IFRC), during a suddenonset disaster. Both a particular operation, the 2006 Yogyakarta earthquake, as well as a more general analysis of IFRC procedures have been studied in order to formalise their business processes in case of emergency.

Our aim is to use a BPMN diagram to better understand the situation and facilitate the construction of an OR model to solve some of the coordination issues faced by the IFRC.

The first step consists in building a business model of relief operations. This model is presented by Fig. 5. The few historical elements on the situation at the IFRC are summarised in the following section.

\subsection{Overview of the situation}

The year 2006 marked a further step in the revitalisation of the IFRC. Its disaster management process had been entirely revised to provide a quicker and better response to disasters. The necessity of improvement in this area had, unfortunately, already been clearly demonstrated for many years. After many adjustments, a radical change had been launched in November 2005: the federation had centralised its policy-making efforts in Geneva and had decentralised its operational capacity by creating three Regional Logistics Units (RLUs) with capacities in terms of mobilisation, procurement, stock and warehousing and fleet support in Dubai, Panama and Kuala Lumpur. Gatignon et al. (2010) To attain the potential benefits of this strategy, efficient coordination was of course required. Indeed, the higher the level of decentralisation, the more critical the effectiveness in coordination. For this application, we studied the first major disaster that the IFRC responded to under this new organisation.

The earthquake happened on the 27th of May, 2006. More than $70 \%$ of the houses and buildings were damaged. Thousands people were injured by in this disaster. The earthquake caused an electrical blackout and, in several areas, the telephone lines were downed, causing severe communications problems. Moreover, all the gas stations were reported to be out of order and some roads and bridges were damaged. In Yogyakarta, 
the international airport was unable to operate and flights to and from the city had to be redirected to Surakarta (60 km from Yogyakarta) or Semarang (120 km from Yogyakarta). The figures totalled 6,000 dead and 1.5 million people affected by the disaster.

During the response phase, the Indonesian Red Cross worked together with the regional logistics unit in Kuala Lumpur and the head quarters in Geneva. Other national societies also participated by sending resources. The British, American, Spanish and Danish Red Crosses sent trained people to give a hand in relief operations. The Japanese, Belgian, Spanish Red Crosses sent goods. In May 2006, Kuala Lumpur RLU had been finalising its implementation. Consequently, during the first days after the earthquake, the global coordination was ensured by Geneva, as it had been done before the decentralisation process. In the beginning of June, however, Kuala Lumpur took the lead in the coordination of the logistics services response, as stipulated by the new organisation.

The IFRCs response process commenced well. Indeed, logisticians were present from the beginning and some stock was also available. In fact, the local delegation was able to benefit from the post-tsunami work in progress at the time and from the fact that Mont Merapi, a volcano $70 \mathrm{~km}$ from Yogyakarta, had become active two months earlier. For these reasons, even though the Kuala Lumpur RLU had not yet been fully operational (no central warehouse with available stock; human resources still lacking), the situation in Yogyakarta (stock and technical staff available) justifies the hypothesis that the actual response to the crisis in Yogyakarta is close to what it would have been had the RLU been 100\% operational (Jahre and Heigh 2008; Charles et al. 2009).

\subsection{Business process modelling}

\subsubsection{Construction of the BPMN}

We discuss in this paper only one model: the functional view through a BPMN. This representation allows the relationships between the HSCs entities to be modelled and the activities that are fulfilled and their sequencing to be described. The scope of our study is represented by Fig. 4.

The model presented in Fig. 5 represents the main business processes run by the Red Cross stakeholders from the end of the response phase and the beginning of the support phase (according to the lifecycle described in Fig. 1) to the end of the relief response. The level of detail used here corresponds to the partial level (see Fig. 4). It is indeed sufficiently general to correspond to other operations than the response of the IFRC to the Yogyakarta earthquake, although it would not correspond to other organisations' operations.

The following were the main entities in operation during the crisis:

- IFRC head quarters (Geneva), which ensure the strategic coordination for this operation but potentially also for other operations in other places.

- The Regional Logistics Unit (RLU), which coordinated operations regionally. Concretely, it consolidated the needs and controlled the pipeline for field distributions 


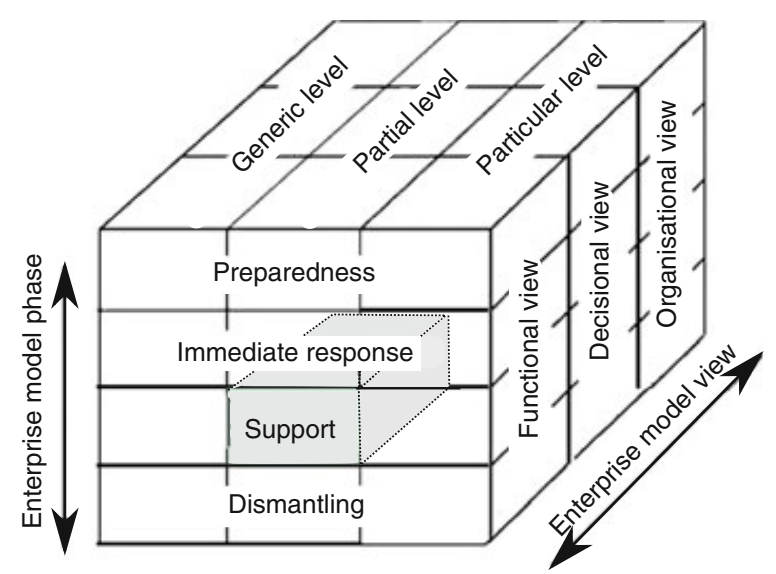

Fig. 4 Overview of the view, phase and level of the business model used in this application

(procurements, central warehousing, etc.). An RLU is also used to coordinate shipments, track what has been done and potentially do the same for other operations in other places.

- The Logistics Emergency Response Unit (ERUlog), composed of members of the British Red Cross in the case of Yogyakarta. They were responsible for reception at the airport, for storage and for execution of shipments in the field.

- The Relief Emergency Response Unit (ERUrelief), composed of members of the American and Spanish Red Cross for this crisis. They helped with the field distribution organisation.

- The local National Society (NS), was responsible for operations, requesting assistance from others where skilled resources were lacking yet acting independently whenever possible. Regarding its role in logistics operations, it procured locally and executed the relief distribution.

\subsubsection{Analysis of the BPMN}

The model presented in Fig. 5 enables to analyse operations. A first positive element is the clear definition of nearly everyone's role. The coordination and responsibilities in each level is well identified and hierarchically structured: global coordination in Geneva, regional coordination in RLUs and local coordination at field level. Coming back to our definition of coordination, in Sect. 2.4, we can assert that their synchronization was quite good.

The model nevertheless illustrates that the main issue faced by the IFRC, that is to say the difficulty to gather timely and accurate data from the field, comes from an organizational gap. Indeed, the activity "to collect information" in the BPMN diagram is connected to other activities by messages. It is not linked in a sequence of operations, and is therefore often neglected. The business process shows that the feedback loop to IFRC in Geneva should be structured more formally. Frequent updates on operations are collected and published on IFRC website by the media centre and a specific logistics software has been designed to increase both traceability and accountability. Despite this, information with regard to the nature, number and status of entities transiting the 


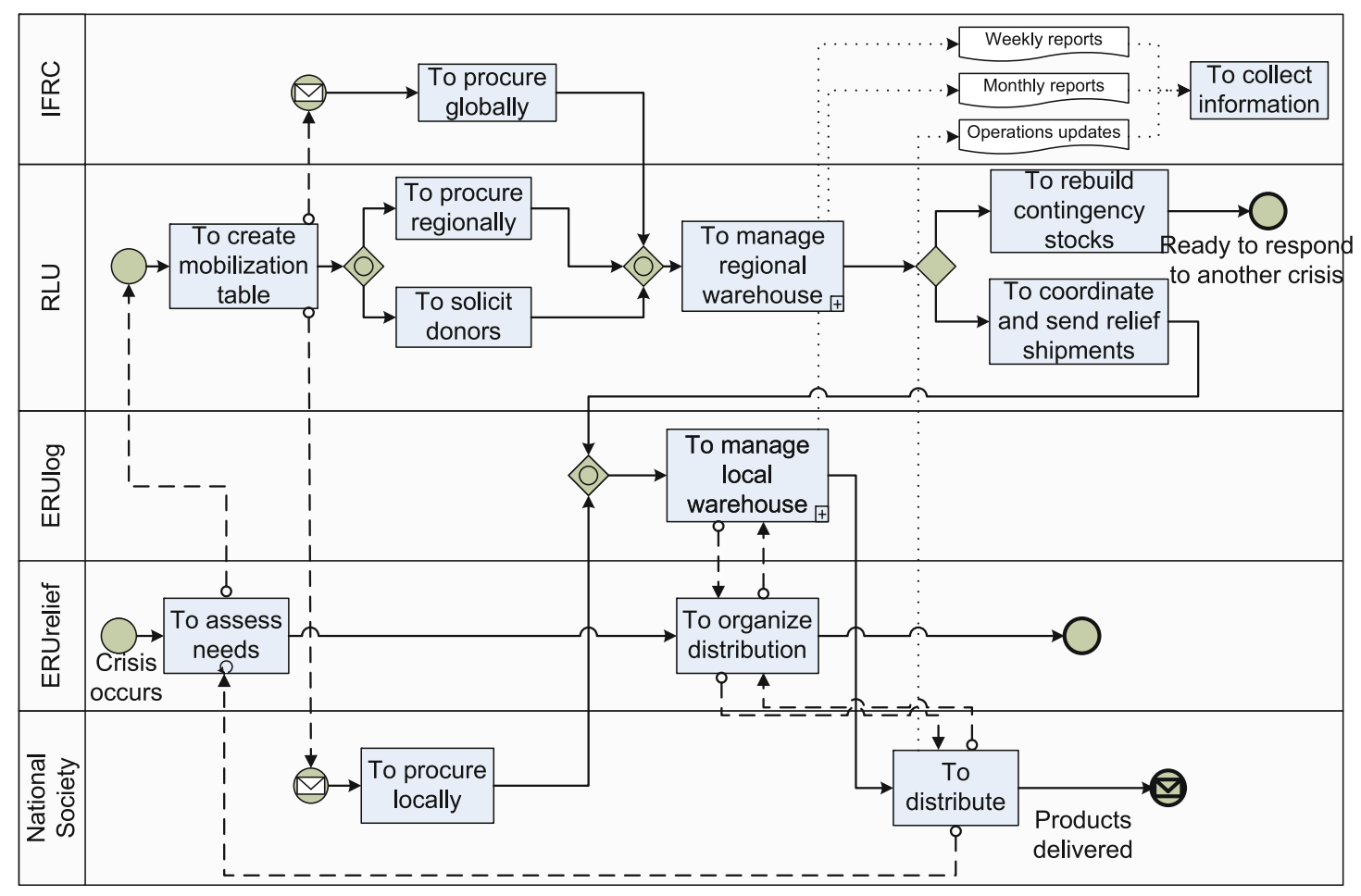

Fig. 5 BPMN of the material flows during IFRC's disaster response process

supply chain is neither tracked nor spread systematically, especially during the last mile delivery.

Regarding the analysis in terms of "balancing" capability, a direct consequence of the previous point is that it is difficult for Geneva to properly allocate funds and skills for field operations. The model underlines a lack of macro-vision and control on the operation. No systematic information loop exists to keep Geneva up to date on a daily basis.

As for the "training" component, a positive element is the presence of pre-defined documents and standards, which allows to clarify and speed up communication processes. On the other hand, the functional model puts forward the role of the ERU relief and the fact that, there again, its activities are not linked with others in a sequence of activities. This garbled situation may be related to the fact that "logistics and resource mobilization" and "disaster management" are two separated department at the IFRC. Relief teams often work as partners with logisticians, but with their own hierarchic systems. This may induce a deficit of training of some logisticians in disaster management.

Of course, this analysis is partial. To be complete, the analysis must consider the remaining modelling views, organisation, and decision and all the life-cycle phases.

\subsection{Quantitative modelling}

In Sect. 2.4, we referred to the three key determinants of coordination; here, we will focus on the synchronisation of activities. To guarantee the coherence and efficiency of relief operations, a mixed integer linear program (MIP) has been built to minimise 
the costs linked to disaster response. Coming back to the humanitarian operations lifecycle presented in Fig. 1, the model developed optimises the synchronization of actors by improving the design of the supply chain and therefore relates to the preparedness phase. This focus on preparedness aims to improve the efficiency of disaster response while taking into account humanitarians constrains detailed in the first three sections of this paper.

\subsubsection{Identification of variables and parameters}

As shown in the model presented in Fig. 5, our second step is to extract the main components of a MIP to analyse the costs of disaster response.

Following the methodology described in Sect. 3.3, we have selected all the core activities, i.e. those that are directly necessary for sending aid to beneficiaries. They are represented by the darker cells of the business model (Fig. 7).

The next step consists in identifying input/output variables and parameters. They result from each activity which actively provides relief to beneficiaries. As for input data, this comes from the remaining activities. This process can be illustrated by two examples.

Let us first consider the activity "to manage regional warehouse". As you can see in Fig. 7 and its excerpt, Fig. 6, three flows are merged before this activity. They represent the reception of products supplied from global and regional suppliers as well as in-kind donations. Input parameters linked with these flows will therefore be delivery time and costs between global suppliers or donors and regional suppliers. As for output parameters, they are directly linked with the accomplishment of the activity. Managing flows has a cost. Fixed and variable costs linked to the management of this regional warehouse are thus listed as parameters here. The costs associated with the management of the flows depend on the quantity of products arriving as well as on the quantity of products already in stock. The variable associated with this activity is thus the quantity of products in stock in the warehouse. The quantities of products arriving in the warehouses are given by each of the preceding activities.

Let us now consider the identification of input data. It comes from activities which participate only indirectly in the actual shipment of relief aid. For example, the assessment of needs is necessary to ensure that what is sent to the field matches the needs of the affected population. Yet its completion or its lack of completion does not affect the flow of products.
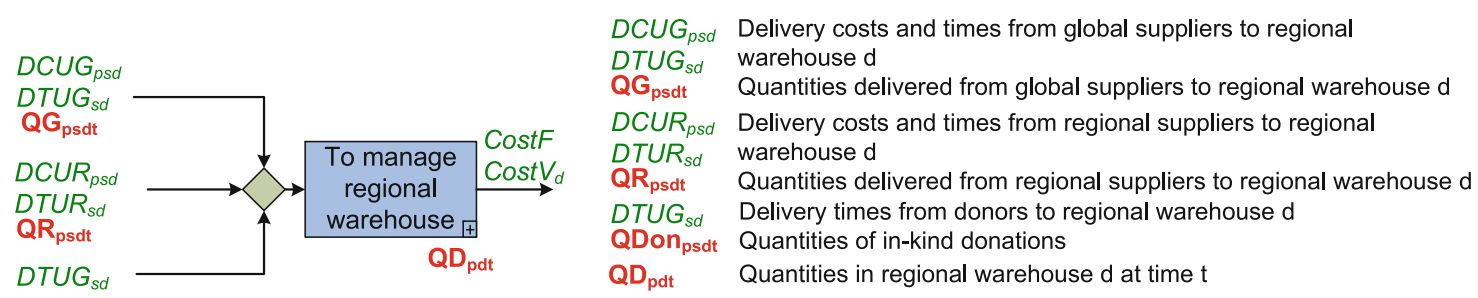

Fig. 6 Details of the second step of our approach 


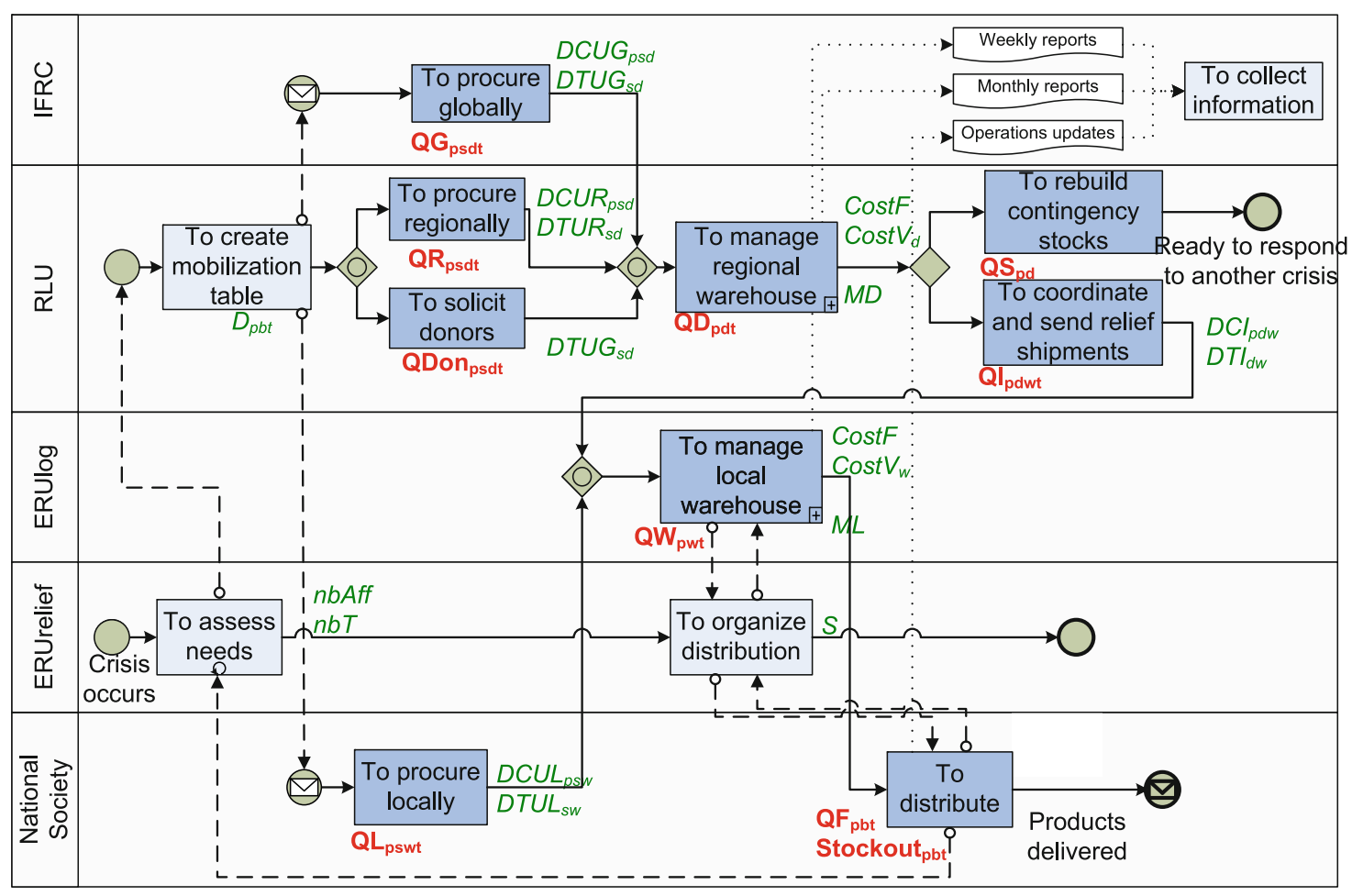

Fig. 7 Illustration of the three steps of our approach: selection of value-added activities, identification of input and output flows and extraction of parameters

\subsection{The resulting mathematical model}

The variables and parameters can be visualised in Fig. 7. The list of variables is written in bold, underneath the activities. As for the parameters, they are written in italic and on the right side of the corresponding activities. Table 2 provides an overview of all the notations we have used. The use of these parameters and variables in an optimisation model is thus facilitated. Our approach enabled us to better understand the situation and focus on core activities.

Let us now look at the quantitative model built using the enterprise modelling approach. As we have seen in the first section of this paper, the more efficient the response, the better the coordination will be. The model we have built therefore minimises the costs associated with the response. In our specific context, the effectiveness of operations is also vital. Need assessment provides the nature and quantities of products necessary and the targeted delivery times. The satisfaction of this demand is taken into consideration as a constraint of the model.

\section{Objective Function}

$$
\begin{aligned}
\operatorname{Min} & \sum_{p} \sum_{s} \sum_{d}\left(\left(\mathrm{DCUG}_{p s d} \times \sum_{t} \mathrm{QG}_{p s d t}\right)+\left(\mathrm{DCUR}_{p s d} \times \sum_{t} \mathrm{QR}_{p s d t}\right)\right) \\
+ & \sum_{p} \sum_{w}\left(\sum_{s}\left(\mathrm{DCUL}_{p s w} \times \sum_{t} \mathrm{QL}_{p s w t}\right)+\sum_{b} \mathrm{DCI}_{p d w} \times \sum_{t} \mathrm{QI}_{p d w t}\right)
\end{aligned}
$$


Table 2 Notations

\begin{tabular}{|c|c|c|}
\hline \multicolumn{2}{|l|}{ Notation } & Definition \\
\hline \multicolumn{3}{|l|}{ Indices } \\
\hline$p$ & & Product \\
\hline$s$ & & Supplier \\
\hline$d$ & & Regional warehouse \\
\hline$w$ & & Local warehouse \\
\hline$b$ & & Beneficiaries, i.e. affected region \\
\hline$t$ & & Time \\
\hline \multicolumn{3}{|l|}{ Parameters } \\
\hline $\mathrm{D}_{p c t}$ & double & Demand of each product to rescue the affected region $c$ at time $t$ \\
\hline $\mathrm{DCUG}_{p s d}$ & double & $\begin{array}{l}\text { Delivery cost to deliver product } p \text { from global supplier } s \text { to regional } \\
\text { warehouse } d \text { (Upstream potential regional warehouse) }\end{array}$ \\
\hline $\mathrm{DTUG}_{s d}$ & double & $\begin{array}{l}\text { Delivery time to deliver a product from donor or global supplier } s \text { to } \\
\text { regional warehouse } d \text { (Upstream regional warehouse) }\end{array}$ \\
\hline $\operatorname{DCUR}_{p s d}$ & double & $\begin{array}{l}\text { Delivery cost to deliver product } p \text { from } \\
\text { regional supplier } s \text { to regional warehouse } d \text { (Upstream regional warehouse) }\end{array}$ \\
\hline $\mathrm{DTUR}_{s d}$ & double & $\begin{array}{l}\text { Delivery time to deliver a product from regional supplier } s \text { to } \\
\text { regional warehouse } d \text { (Upstream regional warehouse) }\end{array}$ \\
\hline $\operatorname{DCUL}_{p s w}$ & double & $\begin{array}{l}\text { Delivery cost to deliver product } p \text { from local supplier } s \text { to local } \\
\text { warehouse } w \text { (Upstream local warehouse) }\end{array}$ \\
\hline DTUL $_{s w}$ & double & $\begin{array}{l}\text { Delivery time to deliver a product from local supplier } s \text { to } \\
\text { local warehouse } w \text { (Upstream local warehouse) }\end{array}$ \\
\hline $\operatorname{DCI}_{p d w}$ & double & $\begin{array}{l}\text { Delivery cost to deliver product } p \text { from regional warehouse } d \text { to } \\
\text { local warehouse } w \text { (Upstream local warehouse) }\end{array}$ \\
\hline $\mathrm{DTI}_{d w}$ & double & $\begin{array}{l}\text { Delivery time to deliver a product from regional warehouse } d \text { to } \\
\text { local warehouse } w \text { (Upstream local warehouse) }\end{array}$ \\
\hline $\operatorname{CostF}_{d}$ & double & Fixed costs to run the regional warehouse \\
\hline $\operatorname{Cost} \mathrm{V}_{d}$ & double & Variable costs to run the regional warehouse \\
\hline $\operatorname{CostF}_{w}$ & double & Fixed costs to run the local warehouse \\
\hline $\operatorname{Cost}_{w}$ & double & Variable costs to run the local warehouse \\
\hline QDon $_{p s d t}$ & double & $\begin{array}{l}\text { Quantity of products } p \text { delivered from donor } s \text { to } \\
\text { regional warehouse } d \text { at time } t\end{array}$ \\
\hline nbAff & integer & Total number of affected \\
\hline nbT & integer & Duration of operations \\
\hline S & double & Penalty costs, per day and per product not delivered on time \\
\hline MD & double & Maximum capacity of the regional warehouse \\
\hline ML & double & Maximum capacity of the local warehouse \\
\hline \multicolumn{3}{|l|}{ Variables } \\
\hline $\mathrm{QG}_{p s d t}$ & double & Quantity of products $p$ delivered from global supplier $s$ to regional warehouse $d$ at time $t$ \\
\hline $\mathrm{QR}_{p s d t}$ & double & Quantity of products $p$ delivered from regional supplier $s$ to regional warehouse $d$ at time $t$ \\
\hline $\mathrm{QL}_{p s w t}$ & double & Quantity of products $p$ delivered from local supplier $s$ to local warehouse $w$ at time $t$ \\
\hline $\mathrm{QI}_{p s w t}$ & double & Quantity of products $p$ delivered from regional warehouse $d$ to local warehouse $w$ at time $t$ \\
\hline $\mathrm{QF}_{\text {pwct }}$ & double & Quantity of products $p$ delivered from warehouse $w$ to the affected region $b$ at time $t$ \\
\hline $\mathrm{QW}_{p t w}$ & double & Quantity in stock of products $p$ in local warehouse $w$ at time $t$ \\
\hline $\mathrm{QD}_{p t w}$ & double & Quantity in stock of products $p$ in regional warehouse $d$ at time $t$ \\
\hline $\mathrm{QS}_{p d}$ & double & $\begin{array}{l}\text { Contingency stocks. Corresponds to a quantity of products } p \text { to keep in stock } \\
\text { at warehouse } d \text { prior to disasters in order to facilitate an immediate response ( } 5 \text { days) }\end{array}$ \\
\hline Stockout $_{p c t}$ & double & Quantity of products $p$ which were not delivered to beneficiary $b$ at time $t$ \\
\hline $\mathrm{WCh}_{w}$ & boolean & $\mathrm{WChw}=1$ if warehouse $\mathrm{w}$ should be opened; $\mathrm{WChw}=0$ otherwise \\
\hline $\mathrm{WCh}_{d}$ & boolean & WChd $=1$ if warehouse $d$ should be opened; WChd $=0$ otherwise \\
\hline
\end{tabular}




$$
\begin{aligned}
& +\sum_{p} \sum_{w} \sum_{b}\left(\mathrm{DCF}_{p w b} \times \sum_{t} \mathrm{QF}_{p w b t}\right) \\
& +\sum_{d}\left(\operatorname{CostF}_{d} \times \mathrm{WCh}_{d}\right)+\sum_{w}\left(\operatorname{CostF}_{w} \times \mathrm{WCh}_{w}\right) \\
& +\sum_{t} \sum_{d} \operatorname{CostV}_{d} \times \sum_{p}\left(\sum_{s}\left(\mathrm{QG}_{p s d t}+\mathrm{QR}_{p s d t}+\mathrm{QDon}_{p s d t}\right)+\sum_{w} \mathrm{QI}_{p d w t}\right) \\
& +\sum_{t} \sum_{w} \operatorname{CostV}_{w} \times \sum_{p}\left(\sum_{s} \mathrm{QL}_{p s w t}+\sum_{d} \mathrm{QI}_{p d w t}+\sum_{b} \mathrm{QF}_{p w b t}\right) \\
& +\sum_{p} \sum_{w} \sum_{b} \sum_{t}\left(\operatorname{Stockout}_{p b t} \times S\right)
\end{aligned}
$$

where

- Line 1 represents transportation costs from global and regional suppliers to regional warehouses;

- Line 2 represents transportation costs from regional warehouses and local suppliers to local warehouses;

- Line 3 represents transportation costs from local warehouses to beneficiaries;

- Line 4 represents the fixed costs of maintaining functioning warehouses;

- Line 5 represents the variable costs incurred in running the warehouses. It is proportional to the quantity of products: the greater the number of products handled by the warehouse, the greater the number of employees required;

- Line 6 represents the penalty costs incurred if products are not delivered on time.

Constraints We then wrote a facility location model, similar to classical facility location models, with one transportation mode and three stages. The constraints of our model impose

1. Either the satisfaction of the demand or the addition of a stock-out cost.

2. The presence of products in a potential warehouse if and only if it is opened.

3. The balance of inventory.

4. The rebuilding of contingency stocks.

5. The fact that existing warehouses are already open.

6. The fact that humanitarian organisations may not have the funding to open too many warehouses at the same time.

7. The fact that regional and local warehouses have limited capacity.

We did not detail the model here, as the originality of this paper lies in the building of the model rather than in the model itself. For further detail on the model itself, on managerial recommendations resulting from this MIP as well as on the sensitivity analysis, the reader is encouraged to have a look at Charles (2010). Thanks to the business model, we quickly built a relevant model, which can then be used to analyse and compare various supply chain configurations. An improvement in the efficiency of the logistics network can then be made using this model. This is not the purpose of this article, however. 
Available facility location models dedicated to the not-for-profit sector mostly focus either on the response phase, like Ozdamar et al. (2004) or on the setting up of prepositioned system locally, like Salmeron and Apte (2010).

Out of all the articles published on facility location dedicated to disaster relief, only three articles take a preparedness point of view and work on the global supply network (Akkihal and Blanco 2006; Balik and Beamon 2008; Lodree and Taskin 2008). Those three papers focus on effectiveness maximisation. None of the facility location model applied to disaster relief deals with efficiency.

This choice between maximizing effectiveness and efficiency is made obvious by Fig. 7. Indeed, Delivery times and delivery costs are the two main parameters underlined by our BPMN. Our approach enabled us to better visualise this possibility to maximise efficiency rather than effectiveness. The focus on efficiency is also in line with the conclusions of the first part of this paper: one of the main issues with regard to the coordination of humanitarian operations arises from their lack of synchronisation. Synchronisation being closely linked with efficiency, or proposed model better answers the needs of humanitarian organisations. This focus on efficiency has also been made explicit by humanitarians. Interviewees, especially at IFRC, insisted that the problem is not to maximise the coverage because plane deliveries allow them to cover wide distances quickly. According to them, the idea is more about how to achieve a given level of effectiveness in the most efficient way. In other words, they would prefer to minimise the costs to meet the demand in specific time-frames, which is the element we retained thanks to our approach.

The usual method of dealing with demand uncertainty is to use a stochastic or robust optimisation model. Yet, if we refer to Shapiro et al. (2009), the stochastic optimisation model optimises the random outcome on average. "This is justified when the Law of Large Numbers can be invoked and we are interested in the long-term performance, irrespective of the fluctuations of specific outcome realizations". In our case, the impact of those "fluctuations" are on human lives and can be devastating. We therefore aligned with the recommendation provided by Shapiro (2000), which is to construct multiple scenarios of an uncertain future and optimise a linear programming model for each scenario. Indeed, according to Shapiro, deterministic optimization of a model of a supply chain planning problem is often the most practical approach. In most planning situations, the development of points (that is, single) estimates of key parameters is difficult enough. For such problems, it is not realistic to attempt to develop extensive descriptions of how the parameters might vary in the future. Although the modeller may sometimes be forced to acknowledge that a deterministic model is imperfect in its description of the future, the benefits of using such a model are still substantial. This choice was also driven by the analysis of our specific application case, disaster relief. Nevertheless, a comparison with other ways to take uncertainty into account should definitively be considered as a topic for future research (Shapiro 2000).

A third element that our methodology underlined is the presence of donated products, which also have a cost for humanitarian organisations. Products have to be stored, 
handled, transported and distributed to the beneficiaries. Those costs are not taken into account in other models dealing with facility locations.

\section{Relevance of the model for humanitarian organisations}

Most of the information we used derives from interviews with practitioners and public databases. Transportation costs and times have been based on quotes provided by a major U.S. transportation company, independently validated by discussions with practitioners from MSF and two private companies. Fixed and Variable costs have been calculated on the basis of regional average salaries and GNI/GDP. Information regarding purchase costs and the locations of suppliers has come from our interviews and the IFRC website. Initial values of parameters, such as the required level of service and the size of the contingency stock, also derive from discussions with IFRC (see Charles 2010 for more details).

Our application has therefore been built with and for humanitarians. This model can be readily applied to other agencies with different data and parameters than the one we used for IFRC. Applications for the UNHRD or world vision have already been developed, though without validation by those organisations.

Our aim was not to find a fundamentally novel way to deal with facility location, but rather to solve humanitarians' practical problems. We used algorithms close to existing ones, but made sure that they take humanitarians' specifications into account. Here again, the reader is encouraged to have a look at Charles (2010) for additional details.

\section{Conclusion}

As we have shown in this paper, practitioners and researchers who want to optimise an HSC are often faced with the problem of establishing an accurate and confident quantitative model. This article tackles the problem by developing a dedicated conceptual enterprise modelling approach.

We started by describing HSC salient features in order to underline the interest of optimisation techniques for this new research area. In particular, the problem of coordination in an HSC has been developed. But the recentness of this topic associated with the low quantity of information available constitute a major difficulty in identifying variables, data and parameters that could be necessary for potential mathematical optimisation.

Inspired by the Enterprise Modelling ISO 19439 standard (AFNOR 2006), we formulated a business process modelling approach that assists in understanding, analysing, evaluating and then developing a formal expression of a HSC. A three-step methodology has been developed to convert conceptual information included in a BPMN model into quantitative information, essential for following optimisation steps. In practical terms the paper illustrated our proposition with the emergency response processes of the IFRC. This application case allowed us to formulate an accurate and confident quantitative model that should help to optimise the coordination capabilities of the IFRC by improving the efficiency of its network. 
Though our proposition constitutes a significant first step towards supporting the optimisation modelling problems encountered in HSC works, many other issues were not addressed and this leaves room for further research. These issues are

1. Our approach should be improved by receiving complementary practitioners insights. In particular, on-going research work consists in implementing our proposition from the modelling step developed in this paper to the optimisation step (Charles 2010). This research work should validate the confidence that humanitarian decision-makers could have in our proposition.

2. We formulated a generic methodology that is able to analyse several points of view of ISO 19439 (AFNOR 2006) standards. In the current paper, however, we develop only the functional view towards some BPMN representations. Consequently, one perspective might be other kinds of business process modelling applications.

3. The problem of black-box optimisation models is not specific to the humanitarian context. Thus, it might be interesting to develop our proposition in other research areas that have a similar difficulty in formalising their quantitative optimisation models: sustainable supply chains or service supply chains, for example.

\section{References}

AFNOR (2001) Enterprise integration-framework for enterprise modelling, European Comitte for Standardization (CEN ENV 40003:1999)

AFNOR (2006) Enterprise integration-framework for enterprise modelling, International Organization for Standardization (ISO 19439:2006)

Akkihal AR, Blanco EE (2006) Inventory pre-positioning for humanitarian operations. Master thesis, The Johns Hopkins University, Baltimore

Altay N, Green LV (2005) OR MS research in disaster operations management. Eur J Oper Res 175(1): 475-493

Arnold T, Chapman SN (2004) Introduction to materials management. Pearson Education, Upper Saddle River

Balcik B, Beamon BM, Krejci CC, Muramatsu KM, Ramirez M (2010) Cordination in humanitarian relief chains: practices, challenges and opportunities. Int J Prod Econ 126(1):22-34

Balik B, Beamon BM (2008) Facility location in humanitarian relief. Int J Logist Res Appl 11:101-121

Barr RS, Helgason RV, Kennington JL (1997) Interfaces in computer science and operations research. Springer, New York

Beamon BM (2004) Humanitarian relief chains: issues and challenges. In: The 34th international conference on computers and industrial engineering, November 14-16, San Francisco, CA

Beamon BM, Balcik B (2008) Performance measurement in humanitarian relief chains. Int J Public Sector Manag 21:4-25

Bender EA (2000) An introduction to mathematical modeling. Dover, New York

Benini AA (1999) Network without centre? A case study of an organizational network responding to an earthquake. J Contin Crisis Manag 7:38

Benini AA, Conley CE, Shdeed R, Spurway K, Yarmoshuk M (2003) Integration of different data bodies for humanitarian decision support: an example from mine action. Disasters 27:288-304

Blecken AF, Hellingrath B (2008) Supply chain management software for humanitarian operations: review and assessment of current tools, Washington, DC, USA. F. Fiedrich and B. Van de Walle

Bui TX, Sankaran SR (2001) Design considerations for a virtual information center for humanitarian assistance/disaster relief using workflow modeling. Decis Support Syst 31:165-179

Chandes J, Pache G (2010) Investigating humanitarian logistics issues: from operations management to strategic action. J Manuf Technol Manag 21:320-340. doi:10.1108/1741038101

Charles A (2010) Improving the design and management of agile supply chains: feedback and application in the context of humanitarian aid. PhD thesis, Toulouse University-Mines Albi. http://ethesis. inp-toulouse.fr/archive/00001333/01/charles.pdf 
Charles A, Van Wassenhove LN, Gatignon A (2009) The Yogyakarta earthquake: IFRCs rst experiences with the decentralized supply chain. INSEAD case study no. 5590

Clay Whybark D (2007) Issues in managing disaster relief inventories. Int J Prod Econ 108:228-235

Cooper MC, Ellram LM (1993) Characteristics of supply chain management and the implications for purchasing and logistics strategy. Int J Logist Manag 4:13-24

Davidson AL (2006) Key performance indicators in humanitarian logistics. Master thesis, MIT

Denizel M, Usdiken B, Tuncalp D (2003) Drift or shift? Continuity, change, and international variation in knowledge production in OR/MS. Oper Res 51(5):711-720. ISSN:0030364X

Gatignon A, Van Wassenhove LN, Charles A (2010) The Yogyakarta earthquake: humanitarian relief through a decentralized supply chain. Int J Prod Econ 126(1):102-110

Gershenfeld NA (1999) The nature of mathematical modeling. Cambridge University Press, Cambridge

Gruninger M, Fox M (1995) The logic of enterprise modelling. In: Bernus P, Nemes L (eds) Modelling and methodologies for enterprise integration. Chapman and Hall, Cornwall

Handfield RB, Nichols EL (2002) Supply chain redesign: transforming supply chains into integrated value systems. FT Press, Upper Saddle River

Hangos KM, Cameron IT (2001) Empirical model building. In: Process modelling and model analysis, vol 4. Academic Press, New York, pp 493-516

IASC (2007) Towards a beneficiary-level assessment of the cluster approach in humanitarian response: proposed framework for Phase 2 of the cluster evaluation. http://www.humanitarianreform.org/Default. aspx?tabid $=457$

Jahre M, Heigh I (2008) Does the current constraints in funding promote failure in humanitarian supply chains?. Supply Chain Forum Int J 9(2):44-54

Kaiser R, Spiegel PB, Henderson AK, Gerber ML (2003) The application of geographic information systems and global positioning systems in humanitarian emergencies: lessons learned, programme implications and future research. Disasters 27:127-140

Kilger C, Stadtler H (2002) Supply chain management and advanced planning: concepts, models, software and case studies. Springer, New York

Kopczak LR, Johnson EM (2004) Can heroes be efficient? Information Technology at the International Federation of the Red Cross. Case Study no 6-0021, Tuck School of Business at Dartmouth

Kovcs G, Spens KM (2007) Humanitarian logistics in disaster relief operations. Int J Phys Distrib Logist Manag 37:99-114

Lodree EJ, Taskin S (2008) An insurance risk management framework for disaster relief and supply chain disruption inventory planning. J Oper Res Soc 59:674-684

Malone TW, Crowsten K (1994) The interdisciplinary study of coordination. ACM Comput Surv 26(1): $87-119$

Mentzer JT, DeWitt W, Keebler JS, Min S, Nix NW, Smith CD, Zacharia ZG (2001) Defining supply chain management. J Bus Logist 22:1-26

Object Management Group (OMG) (2004) Business Process Model and Notation (BPMN). http://www. omg.org/cgi-bin/doc?dtc/10-06-04

Oloruntoba R, Gray R (2009) Customer service in emergency relief chains. Int J Phys Distrib Logist Manag 39(6):486-505

Ozdamar L, Ekinci E, Kuecuekyazici B (2004) Emergency logistics planning in natural disasters. Ann Oper Res 129:217-245

Pettit SJ, Beresford AKC (2005) Emergency relief logistics: an evaluation of military, non-military and composite response models. Int J Logist Res Appl 8:313-331

Refugee Studies Centre (2007) Humanitarian reform: fulfilling its promise? Forced Migr Rev 29. University of Oxford

Safran P (2003) A strategic approach for disaster and emergency assistance. In: Contribution to the 5th Asian Disaster Reduction Center International meeting and the 2nd UN-ISDR Asian Meeting, Kobe, Japan

Salmeron J, Apte A (2010) Stochastic optimization for natural disaster asset prepositioning. Prod Oper Manag 19(5):561-574

Shapiro JF (2000) Modeling the supply chain, 1st edn. South Western College Publication, Cincinnati

Shapiro A, Dentcheva D, Ruszczynski AP (2009) Lectures on stochastic programming. BPR Publishers, New York

Simchi-Levi D, Kaminsky P, Simchi-Levi E (2003) Designing and managing the supply chain. McGrawHill, Irwin. ISBN:0072492562, 9780072492569 
Stapleton O et al (2009a) Funding structures in humanitarian organizations. International Aid and Trade Review

Stapleton O, Martinez AP, Wassenhove LNV (2009b) Last mile vehicle supply chain in the International Federation of Red Cross and Red Crescent Societies. INSEAD working paper no. 2009/40/TOM/ INSEAD

Stephenson M (2005) Making humanitarian relief networks more effective: operational coordination, trust and sense making. Disasters 29:337-350

The Institute for Operations Research and the Management Sciences (INFORMS) (2011) http://www. informs.org/About-INFORMS/About-Management-Science. Accessed 20 Feb 2011

The International Council of Voluntary Agencies (ICVA) (2008) The essential humanitarian reforms. In: 3rd ICVA conference, Geneva

The Sphere Project (2004) Humanitarian charter and minimum standards in disaster response. Geneva. ISBN:92-9139-097-6

Thomas A, Kopczak LR (2005) From logistics to supply chain management: the path forward in the humanitarian sector. Fritz Institute

Tomasini RM, Van Wassenhove LN (2005) Managing information in humanitarian crises: the UNJLC website. INSEAD case study no 5278

Tomasini RM, Wassenhove LNV (2003) Coordinating disaster logistics after El Salvador's earthquakes using SUMA's humanitarian supply management system. INSEAD case study

Tomasini R, Wassenhove LV (2009) Humanitarian logistics. Palgrave Macmillan, New York

Van Wassenhove LN (2006) Humanitarian aid logistics: supply chain management in high gear. J Oper Res Soc 57:475-489

Van Wassenhove LN, Samii R (2003) The United Nations Joint Logistics Centre (UNJLC): the genesis of a humanitarian relief coordination platform. INSEAD case study

Vernadat FB (1996) Enterprise modeling and intergration: principles and applications. Chapman \& Hall, London

W.E.F. The Synergos Institute (2005) Lessons learned from private sector strengthen links in humanitarian suply chain, global giving matters

White SA, Miers D (2008) BPMN modeling and reference guide: understanding and using BPMN. Future Strategies Inc., USA. ISBN:9780977752720 